\title{
EDITORIAL \\ RESEARCH ON TEACHING NURSING: WHERE IS IT?
}

\author{
NS Gwele
}

A number of studies on student selection (Setsoe, 1992; Uys, 1993) have been documented; what actually happens to those who are selected in the teaching/learning situation remains a mystery. What makes them tick, what particular teaching strategies and tactics work? This is what is missing in nursing research.

Just imagine that you are an enthusiastic nurse educator who reads the published research to improve your teaching. You will find very little assistance in the published nurse education articles. Answers to questions such as:

How can I improve transfer of learning from classroom to clinical?

How can I improve problem solving?

What is the best method of clinical evaluation?

are just not addressed.

It is true that opinions and facts about nursing students and the teaching of nursing are available (Gwele, 1994, Makhathini, 1992). Furthermore, descriptions of nursing students' clinical learning experiences (Dürrheim, 1993; Tlakula, \& Uys, 1993) have been done. However, all of these fall short of answering the question "what must I do?". What exactly makes a difference in terms of both academic and clinical performance? What factors in the educative process make a difference where it counts the most - academic achievement and clinical performance? Research on the nature of the educative process in nursing - that's the gap. Only teachers of nursing can close it.

It may be that researchers and/or supervisors feel that classroom intervention studies with less than 30 subjects are not acceptable. A further problem may be the restriction placed on the individual teacher by the total curriculum context. Whatever the problems, nursing education research needs to focus on solutions,instead of just descriptions of the problems.

\section{REFERENCES}

Setsoe G. (1992): Selection of student nurses at Bafokeng Nursing College. CURATIONIS 15, 2, 31-33

MakhathinI J.T. (1992): Problem-solving process with special application to the clinical setting. CURATIONIS 15,2, 24-26

Uys L.R. (1993): Selection criteria predictive of academic success in the first two years of the integrated diploma in nursing. CURATIONIS $16,2,1-4$

Dürrheim R. (1993): Student nurses' perception of the clinical midwifery experience as a leaming environment. CURATIONIS $16,3,1-5$

Tiakula n.c.r. \& Uys L.R. (1993): Nursing sudent's perception of clinical learning experiences as provided by the nursing staff in the wards. CURATIONIS 16, 4, 28-31

Gwele N.S. \& Uys L.R. (1995): Views of leading nurse educators regarding the comprehensive basic nursing programme. CURATIONIS $18,1,5-10$

NS Gwele, RN PhD

Senior Lecturer

University of Natal 